\title{
Improvement of Hardness and Microstructures by Ageing in Shape Memory CuAlNi Alloys
}

\author{
A. Aydogdu, Y. Aydogdu and O. Adigüzel \\ Department of Physics, Firat University, 23169 Elaziğ, Turkey
}

\begin{abstract}
The shape memory $\mathrm{CuAlNi}$ alloys, having a composition near that of $\mathrm{Cu}_{3} \mathrm{Al}$, exhibit disorder-order transition from the disordered bcc $\beta$-phase to the ordered $\beta_{1}$-phase $\left(\mathrm{DO}_{3}\right.$ type $)$ at high temperatures. Although the $\beta_{1}$-phase is a non-equilibrium phase, it nonetheless remains stable at room temperature upon quenching from the high temperature $\beta$-phase. At the lower temperatures, the $\beta_{1}$-phase itself undergoes martensitic transformation and displays layered structure called M18R. The influence of ageing on two CuAINi $\beta$-phase alloys was studied by measuring the time dependence of hardness, lattice parameters and by.optical microscopy observation at room temperature. Hardness shows a trend to decrease with the ageing duration due to the formation of precipitation, and grain size is also affected by ageing.
\end{abstract}

\section{INTRODUCTION}

Shape memory behaviour is the ability of certain materials to recover the original shape on heating over the austenite start temperature. Although copper-based shape memory alloys are susceptible to low temperature ageing effects which can radically alter the transformation behaviour, CuAlNi shape memory alloys are known to exhibit a better thermal stability than $\mathrm{CuZnAl}$ alloys and this characteristic makes them suitable to be used in applications above $373 \mathrm{~K}$, which is the limit for the $\mathrm{CuZnAl}$ alloys $[1,2,3]$. These alloys are more stable at high temperatures than $\mathrm{CuZnAl}$ alloys, raising the upper temperature limit of operation for shape memory devices, and they are claimed to be less prone to martensite stabilization [4].

As a high temperature shape memory material, CuAlNi alloys have attracted widespread interest; effects of heat treatment on the transformation and mechanical behaviour $[5,6,7]$. For the optimization of shape memory alloys and improvement of hardness, Treppmann and Hornbogen have reported that different properties have to be connected such as optimization of functional qualities and structural properties [8].

Copper based alloys exhibit shape memory within a certain range of composition which have the disordered bec structure, called $\beta$-phase, stable at high temperature and two successive ordering transitions during cooling. They are usually quenched to retain the $\beta$-phase for further transformation to martensite $[9,10]$. Although the studies on shape memory $\mathrm{CuAlNi}$ alloys remain insufficient, it has been found that properties of these alloys are superior to those of $\mathrm{CuZnAl}$ alloys from some viewpoints $[2,11]$. The working temperature of $\mathrm{CuAlNi}$ alloys can be adjusted within a wider range, this indicates more thermal stabilization with increase of ageing duration, and possesses more stable memory character $[3,9,12]$.

In the earlier studies, it was reported that the ageing time effectively plays an important role in the degree of reversion of the alloy shape $[9,13]$. Cu-based shape memory alloys are susceptible to low temperature ageing effects which can radically alter their transformation behavior. Ageing of the martensite reduces both the amount of shape recovery and extent of the reverse transformation. High martensite heating rates promote complete shape recovery and reverse transformation while the ageing occurring during slow heating can inhibit or prohibit both $[1,14]$.

In the present study, the effect of ageing on lattice parameters and hardness in the martensite state of two CuAINi alloys have been investigated and metallographic observations have been performed using optical microscopy. 


\section{EXPERIMENTAL PROCEDURE}

Two shape memory CuAINi alloys were supplied by TREFIMETAUX Centre' de Recherche (France). These alloys were labeled Alloy 1 and Alloy 2; Alloy 1 with a nominal composition of $85.18 \mathrm{wt} \% \mathrm{Cu}$, $11 \mathrm{wt} \% \mathrm{Al}, 3.82 \mathrm{wt} \% \mathrm{Ni}$ and Alloy 2 with a nominal composition by weight of $85.62 \% \mathrm{Cu}, 11 \% \mathrm{Al}$, $3.38 \% \mathrm{Ni}$. All specimens obtained from these alloys were solution treated in the $\beta$-phase equilibrium region ( 30 minutes at $930^{\circ} \mathrm{C}$ for the Alloy 1 and 30 minutes at $920^{\circ} \mathrm{C}$ for the Alloy 2 ) then quenched in iced brine to retain the $\beta$-phase and given the following post-quench heat treatments;

Alloy 1: a) Ageing at room temperature directly after quench,

b) Ageing at room temperature after intermediate anneal at $330{ }^{\circ} \mathrm{C}$ for 30 minutes.

Alloy 2: a) Ageing at room temperature directly after quench and

b) Ageing at room temperature after intermediate anneal at $280^{\circ} \mathrm{C}$ for 30 minutes.

a) XRD Measurements: Powder specimens of alloys were prepared and sealed in evacuated quartz capsules. X-ray powder diffractograms were taken from the as received and heat treated specimens at intervals during martensite ageing using filtered $\mathrm{Cu}-\mathrm{K}_{\alpha}$ radiation at a scanning rate of $2 \% \mathrm{~min}$.

b) Vickers Hardness: Specimens from both alloys were prepared, and Vickers hardness measurements were made. These measurements were performed using an Ernst Leitz GMBH D-6330 Wetzlar hardness tester machine. The applied load was $200 \mathrm{~g}$ and the samples for each ageing time were tested with four indentations on each sample.

c) Metallographic observation: For optical microscopy, the specimens were polished using conventional procedures and etched in a solution composed of $50 \mathrm{~g}\left(\mathrm{FeCl}_{3}-6 \mathrm{H}_{2} \mathrm{O}\right)$ and $960 \mathrm{ml}$ methanol in $200 \mathrm{ml} \mathrm{HCl}$. These specimens were examined in a Reichert $\mathrm{MeF}_{2}$ optical microscope.

\section{RESULTS AND DISCUSSION}

Two shape memory $\mathrm{CuANi}$ alloys investigated in this study are fully martensitic at room temperature, the $\mathrm{A}_{\mathrm{s}}$ temperature is $157^{\circ} \mathrm{C}$ and $58{ }^{\circ} \mathrm{C}$ for Alloy 1 and Alloy 2, respectively [7,15]. Indexed $\mathrm{x}$-ray diffractograms of both alloys in as-quenched and intermediate annealed cases show that these alloys have the modified orthorombic M18R structure in martensitic condition [7]. X-ray diffractograms taken from the powder samples of Alloy 1 are shown in Figure 1 ( $a$ and $b$ ) in as-received and quenched cases, respectively. As seen from x-ray diffractogram in Figure 1a, Alloy 1 has the disordered crystal structure in the as-received case while the heat treated specimens exhibit superlattice reflections as shown in Figure $1 b$. $\mathrm{X}$-ray diffractograms of Alloy 2 are also similar.

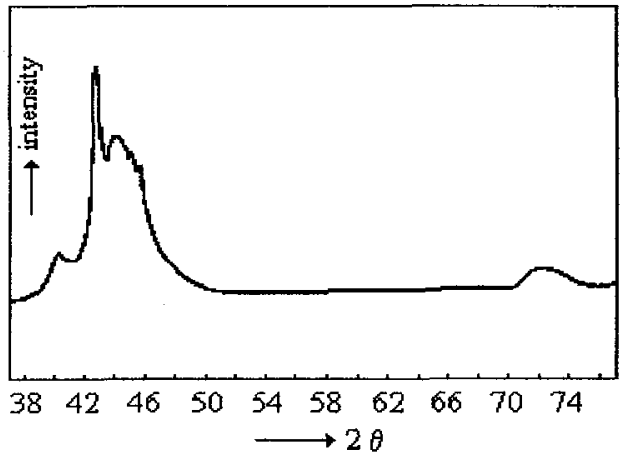

$-\mathbf{a}-$

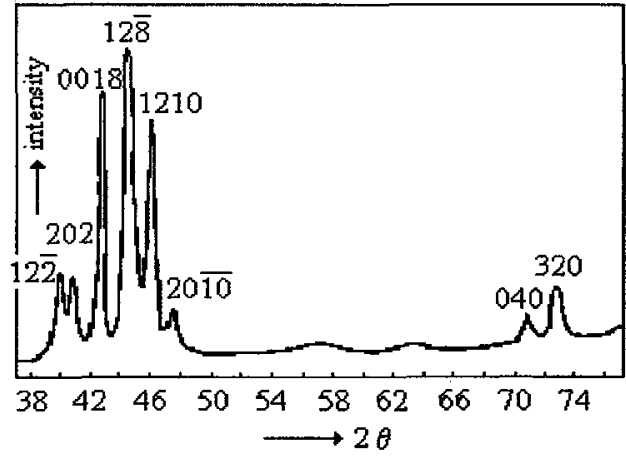

$-b-$

Figure 1: X-ray powder diffractograms taken from the as-received (a) and as-quenched (b) specimens of Alloy 1. 
$X$-ray diffractograms of the quenched samples of the alloys have been indexed on the basis of modified orthorombic M18R unit cell, and lattice parameters of the alloys were calculated by the following relation:

$$
\frac{1}{d^{2}}=\frac{1}{a^{2}}\left(\frac{h^{2}}{\operatorname{Sin}^{2} \beta}\right)+\frac{k^{2}}{b^{2}}+\frac{1}{c^{2}}\left(\frac{1^{2}}{\operatorname{Sin}^{2} \beta}\right)-\frac{2 h 1 \operatorname{Cos} \beta}{a c \operatorname{Sin}^{2} \beta}
$$

and the variations of $a / b$ ratios with ageing time at room temperature have been plotted in Figure 2 for both alloys after quenching and step annealing; $\beta$ is $89.67^{\circ}$ and $89.36^{\circ}$ for Alloy 1 and Alloy 2, respectively. The martensitic phase in copper based $\beta$-phase alloys is based on one of the $\{110\}_{\beta}$ basal planes. In the case where the constituent atoms are randomly distributed in the basal plane, the ratio $a / b$ of the lattice parameters should be equal to $\sqrt{3} / 2$ while the value of this ratio is less than $\sqrt{3} / 2$ in the ordered case due to the atomic sizes of the constituent atoms for $18 \mathrm{R}$ martensite $[9,16,17]$. As seen from Figure 2

( $a$ and $b$ ), $a / b$ ratio is smaller than $\sqrt{3} / 2$ for both alloys in as-quenched and step annealed cases and both of the alloys have an ordered state inherited from the ordered parent phase existing prior to the transformation. The ratio of $a / b$ changes during the early stages of ageing and reaches almost constant values. This result indicates that the martensite is progressively stabilized. The stabilization of the martensite is aided by the quenched in vacancies and this also requires that a structural change occurs during the ageing in the martensitic condition and this gives rise to a change in the configurational order. Although martensitic transformations have a diffusionless character, the stabilization process requires the diffusion during the ageing in the martensitic condition.

The variation of Vickers hardness with holding duration at room temperature for quenched and step annealed samples of Alloy 1 is shown in Figure 3 ( $a$ and $b$ ). The hardness shows a trend to decrease with holding time in the quenched case while no significant change is observed for the step annealed sample. In the as-quenched case Vickers hardness was measured in a range between $321 \mathrm{H}_{\mathrm{v}}$ and $386 \mathrm{H}_{\mathrm{v}}$, this range is between $281 \mathrm{H}_{\mathrm{v}}$ and $300 \mathrm{H}_{\mathrm{v}}$ for as-received alloy samples [15]. The variation of Vickers hardness for both of the heat treated samples of Alloy 2 as Alloy 1 is shown in Figure 4 ( $a$ and $b$ ). These changes also show similar behaviour with those of Alloy 1 . In the as-received case, Vickers hardness was measured in a range between $230 \mathrm{H}_{\mathrm{v}}$ and $248 \mathrm{H}_{\mathrm{v}}$, this range is between $301 \mathrm{H}_{\mathrm{v}}$ and $396 \mathrm{H}_{\mathrm{v}}$ in as-quenched case [15]. One can say from this result that Vickers hardness gradually decreases with ageing time after quenching and almost the remains constant in the step annealed case for both of the alloys. These results are in good agreement with the results reported earlier $[3,18,19]$.

Optical micrographs taken from the samples of both alloys in the as-received case without heat treating are shown in Figure 5 ( $a$ and $b$ ). As seen from these figures, the micrograph of Alloy 1 includes grains and martensite plates while that of Alloy 2 does not include any martensite plate and in contrast it includes intensive precipitates. Optical micrographs taken from the as-quenched sample of Alloy 1 are shown in Figure 6a. As seen from this figure, grains appear clearly and martensite plates have the different orientations in different grains. Martensites are formed in a V-shape in some grains while occurring needlelike in others. It is also observed that grains grow with ageing time. Figure $6 \mathrm{~b}$ also shows the optical micrograph of the same sample after about 150 hours ageing. Grains in the aged case are quite big compared to those of in as-quenched case. Both $\mathrm{x}$-ray diffractograms and optical micrographs taken from the as-received samples reveal that the alloys have the disordered structure in the as-received case. They become ordered on solution treating and undergo martensitic transformation on quenching.

Optical micrographs of the samples of Alloy 2 are seen from Figure 7 ( $a$ and $b$ ) in as-quenched and aged cases, and they also exhibit similar behaviour. The grains of Alloy 2 are very big compared with those of Alloy 1 samples. As seen from the optical micrographs, self accommodated martensite plate groups form in the as-quenched case and grains grow with annealing duration in both of the alloys. These results are in agreement with the observations made by other workers [20-22]. 


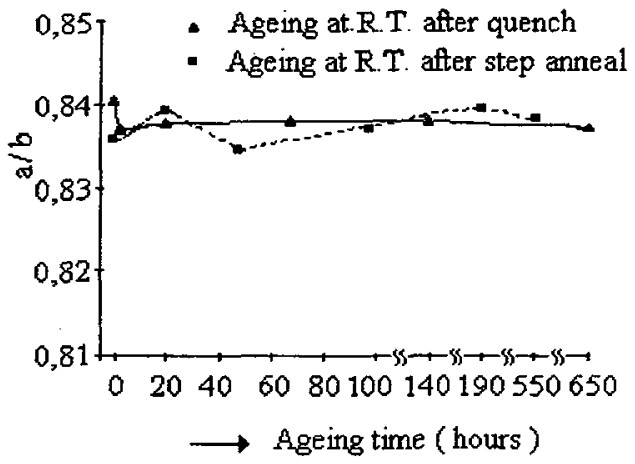

a)

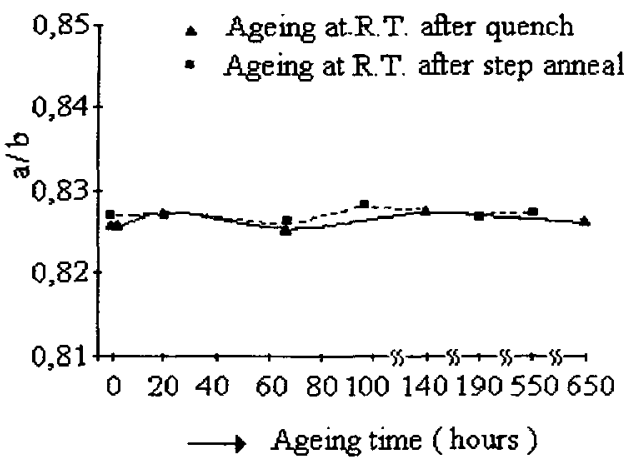

b)

Figure 2: The variation of $a / b$ values of a) Alloy 1 and b) Alloy 2 samples against the ageing time at room temperature

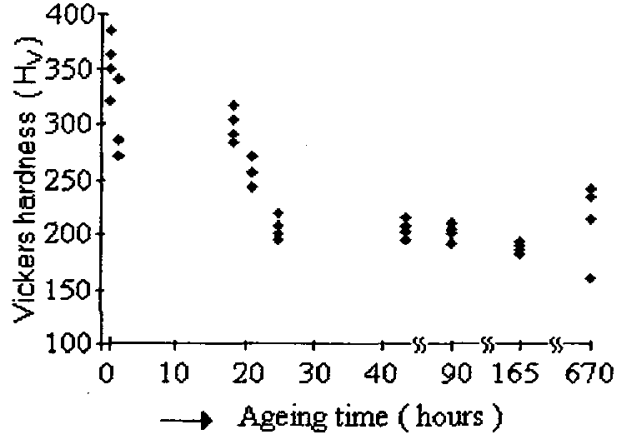

a)

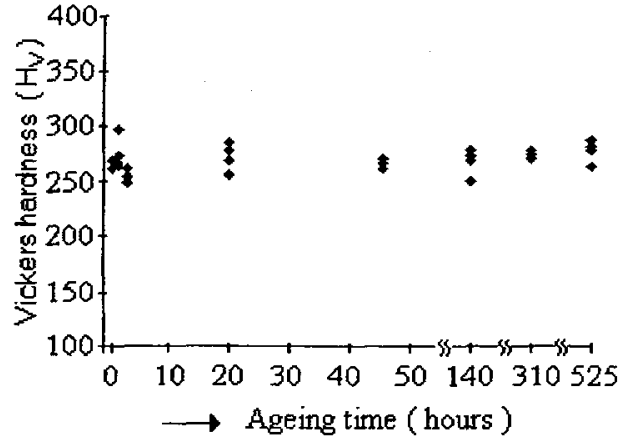

b)

Figure 3: The variation of Vickers hardness with the holding duration at room temperature for a) quenched and b) step annealed ( at $330^{\circ} \mathrm{C}$ for 30 mins) samples of Alloy 1

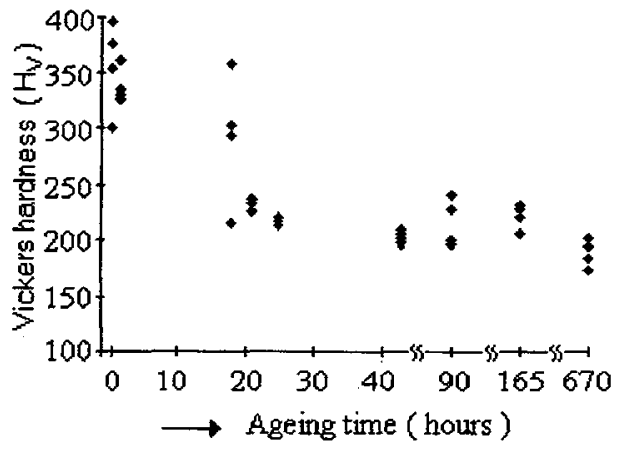

a)

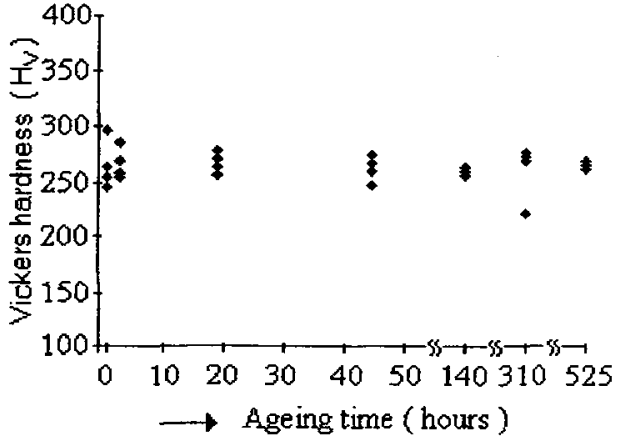

b)

Figure 4: The variation of Vickers hardness for Alloy 2 with the holding time at room temperature a) ageing at R.T. after quenching b) ageing at R.T. after annealing at $330^{\circ} \mathrm{C}$ for 30 mins. 


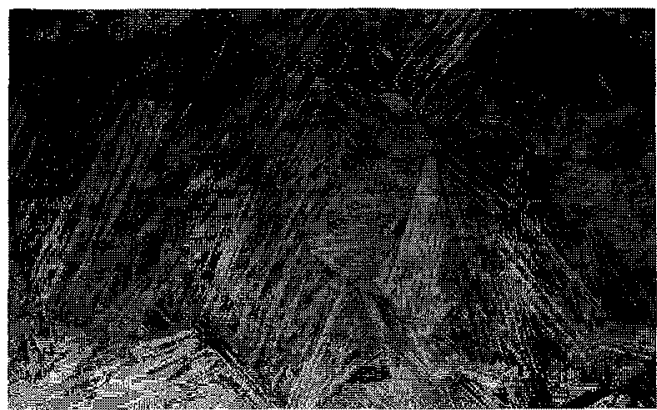

a)

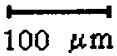

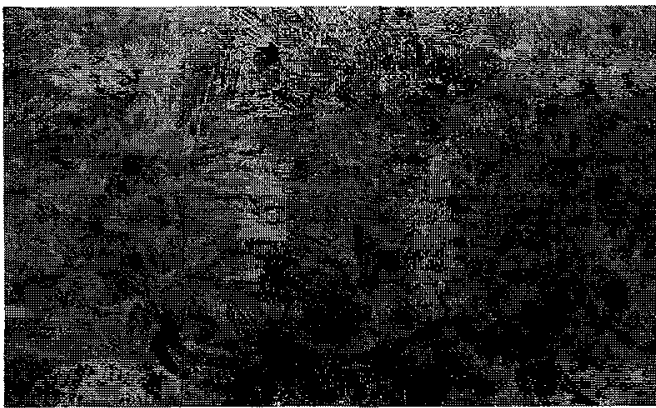

b)

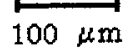

Figure 5: Optical micrographs of etched samples of a) Alloy 1 and b) Alloy 2, in as-received case.

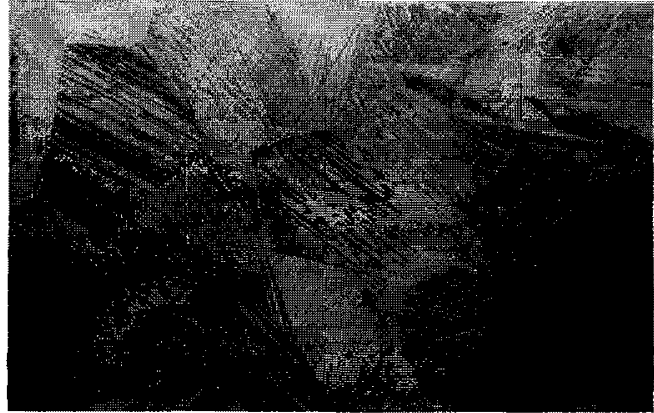

a)

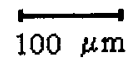

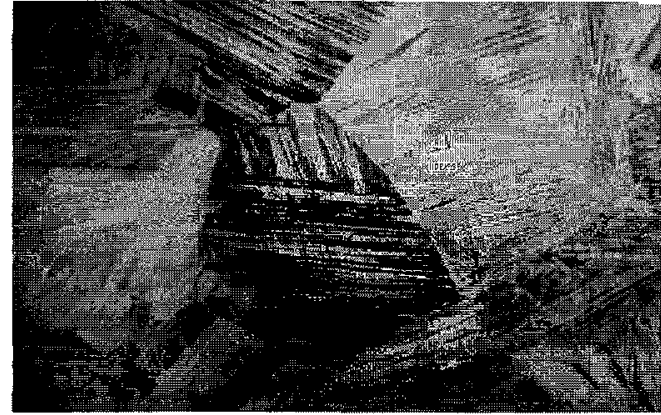

b)

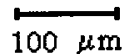

Figure 6: Typical martensite structures and grains obtained from the Alloy 1; a) after cooling and b) after keeping 150 hours at room temperature.

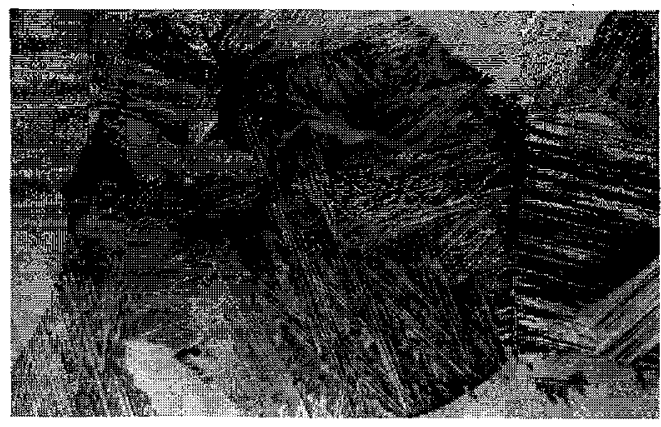

a)

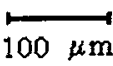

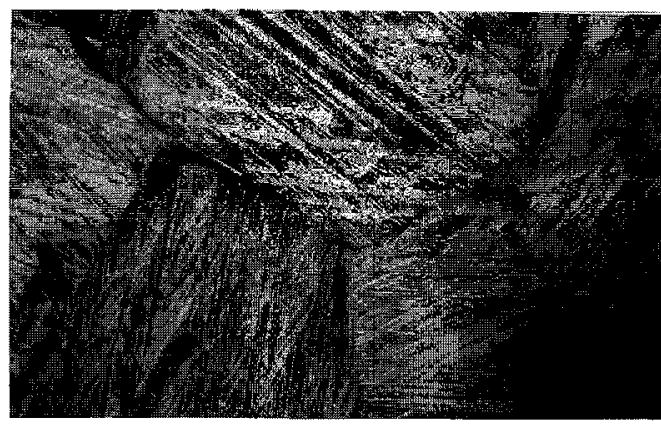

b)

Figure 7: Examples of martensite structures and grains in Alloy 2; a) in as-quenched case and b) after annealing for 14 hours at R.T. 


\section{CONCLUSIONS}

It can be concluded from the above results that $a / b$ ratios of both alloys do not change with ageing duration and alloys remain ordered. The increases in hardness reveal that any precipitation does not occur during ageing and martensites form as a rule exhibiting self-accommodated morphology. Hardness remains stable in the step annealed case and step annealing improves the hardness.

\section{References}

[1] Scarsbrook G., Cook J.M., and Stoobs W.M., Metall. Trans. A, 15A (1984) 1977-1986.

[2] Hurtado I., Van Humbeeck J. and Delaey L., "Stabilisation Processes in a Cantim Alloy", Journal de Physique IV, 1 (1991) C4-247.

[3] Kennon N. F., Dunne D.P. and Middleton L., Metall. Trans. A, $13 A$ (1982) 551-555.

[4] Segui C. and Cesari E., "Effect of $\mathrm{Mn}$ on Ageing of $\mathrm{Cu}-\mathrm{Al}-\mathrm{Ni}-\mathrm{Mn}-\mathrm{B}$ Alloys", Journal de Physique IV, 5 (1995) C2-187.

[5] Qingfu C., Hurtado I., Stalmans R. and Van Humbeeck J., "Stabilisation of Martensite During Training of Cu-Al-Ni Single Crystals", Journal de Physique IV, 5 (1995) C2-181

[6] Sakamoto H. and Shimizu K.H., Mem. Inst. Sci. Ins. Res. Osaka Univ., 46 (1989) 99-110.

[7] Aydogdu A., Aydogdu Y. and Adiguzel O., Materials Research Bulletin, 32, 5, 507-513 (1997)

[8] Treppmann D. and Hornbogen E.,"The Effect of Dislocation Substructure and Decomposition on the Course of Diffusionless Transformations", Journal de Physique IV, $\underline{5}, \mathrm{C} 2-211$ (1995).

[9] Adiguzel O., Materials Resarch Bulletin, $\underline{30}, 755$ (1995).

[10] Kayalı N., Ozgen S. and Adiguzel O., Materials Research Bulletin, 32, 5 , 569-578 (1997).

[11] Xinming Z., Xiong L., Yun Z., Jialong M. and Yuantao N., A Study on Cu-Al-Ni Shape Memory Alloys. Shape Memory Alloy '86, Proceedings of the International Symposium on Shape Memory Alloys, China Academic Publishers, (1986) 261-266.

[12] Chandrasekaran M., Cesari E., Wolska J., Hurtado I., Stalmans R. and Dutkiewicz J., "Stabilisation of Martensite in Copper Based Shape Memory Alloys", Journal de Physique IV, (1995) C4-143.

[13] Adigüzel O., Chandrasekaran L. and Miodownik A.P., "The Role of Ordering in the Loss of Shape Memory in some Copper-base Alloys", The Martensitic Transformation in Science and Technology (Eds. E. Hornbogen and N. Jost), DGM Informations Gesellshapt, Verlag, Germany, (1989)109-114.

[14] Stice J.D. and Wayman C.M., Metall. Trans. A, 13A, (1982) 1687-1697.

[15] Aydogdu A., Ph-D Thesis, Furat University, Elazıg-Turkey (1995) (in Turkish).

[16] Xuan Q., Bohong J. and Hsu T.Y., Materials Science and Engineering, 93 (1987) 205-211.

[17] Kayalı N., Özgen S. and Adıgüzel O., present conference.

[18] Cho Y.R., Kim Y.H. and Lee D.T., Journal of Materials Science, 21 (1991) 2879-2886.

[19] Husain S.W, and Clapp P.C., Metall. Trans. A, 19A (1988) 1761-1766.

[20] Husain S.W., Clapp P.C. and Ahmed M., "Phase Transformations on Agening Cu-Al-Ni $\beta$ Phase Alloys", Materials Resarch Society Symposia Proceedings, 21 (1984) 729-734.

[21] Delaey L., Deruyttere A., Aernoudt E. and Ross J.R., "ShapeMemory Effect, Superelasticity and Damping in Copper-Zinc-Aluminium", INCRA Report R1, (1978) Belgium.

[22] Kayalı N., Ph-D Thesis, Frat University, Elazıg-Turkey (1993) (in Turkish). 